$\underline{\text { Review Article }}$

\title{
AN OVERVIEW ON INFECTION PREVENTION AND CONTROL PRACTICES AND BIOMEDICAL WASTE MANAGEMENT (BMWM) IN COVID-19 ERA
}

\author{
RAVI PRAKASH SHARMA', SIDDHARTHA DUTTA², GOVIND MISHRA², HINA LAL ${ }^{2}$, TARUN KUMAR², ANU \\ SHARMA $^{*}$
}

${ }^{1}$ Department of Pharmacology, All India Institute of Medical Sciences (AIIMS), Jodhpur, Rajasthan, India, ${ }^{2}$ Department of Pharmacology, All India Institute of Medical Sciences (AIIMS), Jodhpur, Rajasthan, India, ${ }^{3} \mathrm{Dr}$. V. M. Govt. Medical College, Solapur, Maharashtra Email: dranusharma2014@gmail.com

Received: 13 Jul 2020, Revised and Accepted: 11 Sep 2020

\section{ABSTRACT}

The ongoing Coronavirus disease (COVID-19) pandemic has affected the almost entire world and has hit the healthcare and economic sector with a hard blow. The Government imposed lockdowns in almost all part of the world has not only affected the global economy but also has harsh effects on physical and mental health of people around the world. To date, there is no specific and defined treatment or vaccine available for its prophylaxis and treatment; hence preventive strategies like Infection prevention and control (IPC) practices and proper disposal of biomedical waste (BMW) play key role in preventing transmission of the infection in the healthcare sector among healthcare professionals. Ethically, we all should follow the IPC and BMW guidelines soulfully to prevent ourselves and fellow workers from getting infected. The review highlights the salient features of the IPC and BMWM (Biomedical waste management) practices in concise manner for better understanding and implementation at this crucial period of COVID-19 pandemic.

Keywords: COVID-19, Pandemic, IPC (Infection prevention and control), BMW (Biomedical waste), BMWM (Biomedical waste management)

(C) 2020 The Authors. Published by Innovare Academic Sciences Pvt Ltd. This is an open access article under the CC BY license (http://creativecommons.org/licenses/by/4.0/) DOI: http://dx.doi.org/10.22159/ijcpr.2020v12i6.40282. Journal homepage: https://innovareacademics.in/journals/index.php/ijcpr Speedy peer review was done as the subject of the manuscript was related with pandemic.

\section{INTRODUCTION}

The virus Severe acute respiratory syndrome coronavirus 2 (SARSCoV-2) is responsible for the current Coronavirus disease (COVID19) pandemic, which has affected almost every country of the world [1]. It has affected almost 213 countries of the world, with a total of 21.2 million active cases and 7,65000 deaths worldwide (as on August 15, 2020) [2]. The primary mode of transmission of COVID19 is through droplet released during coughing or sneezing or via close contact with the infected person [3]. A lot of molecules are being tried, but we are yet to find definite prophylaxis or cure for this highly infectious disease. In view of such scenario, preventive strategies play a crucial role from getting infected from this virus. A physical distance of at least two meters between two persons is advocated by the world health organization (WHO) in order to avoid transmission of the infection [4]. Respiratory droplets can travel short distances and due to gravity, may settle down on inanimate objects and surfaces around the proximity of the infected person which might infect other persons if they touch these objects or surfaces and then touch their face, nose or mouth [5].

At present the treatment of patients with COVID-19 is symptomatic and supportive, as there are no specific drug or vaccines approved for this disease [6]. Adherence to preventive practices are the cornerstone in breaking the transmission chain; therefore, infection prevention and control (IPC) practices along with proper disposal of biomedical waste (BMW) generated in health care facility, isolation wards, quarantine camps play key role in the disease control [7].

Biomedical wastes generated in a health care facility comprise of contaminated blood bags, needles, syringes, body fluid, dressings, plaster casts, cotton swab etc. these are hazardous as they have potential infective microbes present in them. It can directly infect an individual through skin contact, inhalation if not managed properly. Viruses like HIV, Hepatitis B and C COVID-19 can be present in such waste and may cause infection in persons who do not have the disease. So proper steps of segregation, storage, transport and disposal is necessary to avoid such infections.

After reviewing the guidelines laid down by Central Pollution Control Board (CPCB) of India along with a comprehensive literature review on infection prevention and control practices and BMWM
(Biomedical waste management) using search portals like Pubmed, Goggle scholar etc., this article highlights all crucial aspects of IPC practices and BMWM in context of COVID-19 in a concise manner for better understanding and implementation of the same.

This review is based on the current knowledge of Coronavirus disease and existing biomedical waste disposal practices for the management of infectious waste. Indiscriminate disposal of such waste generated during diagnosis, treatment or testing of COVID-19 patients has a potential to spread not only to the municipal workers involved in disposal of such waste but can cause infection among health care workers (HCW), patients and may even contaminate environment resulting in further dissemination of the infection in the community. Therefore as HCW we are morally and ethically responsible in sensitizing people in the community about preventive measures and biomedical waste disposal practices that can be even followed by patients who are quarantined at home.

Biomedical waste management in the current context of COVID-19

Although India already has established BMWM rules right from 2016, the Central Pollution Control Board (CPCB) of India has recently released specific guidelines to ensure safe disposal of BMW generated during treatment, diagnosis or quarantine of patients with COVID-19 infection [8]. These guidelines provide us with steps for safe disposal of waste generated in the health care facility (HCF), testing centers, quarantine facilities and homes of suspected persons. The guidelines also explain in details about the responsibilities of Common biomedical waste treatment facility (CBMWTF), duties of State Pollution Control Board (SPCB), Pollution control board (PCC), Urban local Bodies (ULB).

Following are few highlights and salient points mentioned in the "Guidelines on preventive measures to contain spread of COVID-19 in workplace Settings" for handling, treatment and disposal of waste generated during treatment, diagnosis or quarantine of patients with COVID-19 infection in HCF, testing centers, quarantine facilities and homes of suspected persons.

In the context of COVID-19, biomedical waste like used masks, gloves and tissues or swabs contaminated with blood or body fluids 
of COVID-19 patients should be considered as biomedical waste and treated as per the guidelines laid by the CPCB/SPCB. It is recommended that dedicated separate colour coded bins with footoperated lids should be used for disposal of such waste. These bins should be labelled as COVID-19 waste to identify waste easily so that the waste disposal is done on a priority basis The BMW generated need to be stored separately in a temporary storage room before disposal to CBMWTF. Colour coded non-chlorinated bags to be used in double-layered to avoid leakage. There should be separate record of waste generated from COVID-19 in HCF, testing centers, quarantine facilities and homes of suspected persons to be maintained. There should be dedicated trolleys and collection bins for the collection of such wastes, the surfaces of these trolleys and bins need to be disinfected frequently with $1 \%$ hypochlorite solution. Segregation of BMW from general waste should be done at the point of generation. General solid waste should be collected separately as per SWM (Solid Waste Management) Rules 2016. Use of dedicated vehicles for collection of COVID-19 waste and proper sanitization of the vehicle after every trip.

Used masks, tissues and toiletries of COVID-19 patients to be disposed of in yellow bag. While Masks and gloves used by persons other than the COVID-19 patients should be kept in paper bag for 72 $\mathrm{h}$ and then disposed with general waste after cutting them to prevent re-use. In case of home care of suspected COVID-19 patients, BMW to be collected separately in non-chlorinated yellow bags and handed over to an authorized waste collector. The ULB's should engage CBMWTF's to either pick such waste directly from such houses or to collect such waste from a common collection point.

It is recommended that prior intimation of opening or operation of ward, sample collection or testing center to the SPCB should be done. Equipment's used during testing of COVID-19 samples need to be pre-treated these includes viral transport media, plastic vials, vacutainers, eppendorf tubes, pipette tips are to be disposed in red bag (as per BMW Rules 2016).

It is the responsibility of CBMWTF is to inform SPCB about receiving such waste and to ensure that proper record of collection, treatment and disposal of COVID-19 waste is maintained. The records of waste management and disposal to be updated regularly on COVID19BMW mobile application. CBMWTF operators should also ensure proper training and sanitization of persons involved in handling such wastes. They should also ensure that appropriate PPE (personal protective equipment) kit should be available to all person involved in the collection and handling of such wastes. Any worker showing symptoms of illness should not be allowed to work in the facility.

The responsibilities of SPCB/PCC include maintenance of records of COVID-19 from HCF, Quarantine centers, Quarantine homes of their states and to co-ordinate with CBMWTF and ULB's to establish facilities for collection and disposal of COVID-19 waste. As the amount of BMW generated is more than the usual conditions SPCB/PCC should allow CBMWTF to operate for extra hours if required. Every SPCB/PCC should use the mobile application COVID19 BMW to submit daily data to CPCB. As per the information available at the CDC (Centers for Disease Control and Prevention) U. $\mathrm{S}$. A, the risk of transmission of virus through sewage is low. Therefore, it is recommended that HCF's and agencies operating STP (Sewage Treatment Plant) should continue to follow routine practices like the disinfection of wastewater prior to disposal.

\section{Infection prevention and control (IPC) practices for COVID-19}

Infection prevention and control (IPC) is the practice of preventing spread of infection during health care delivery in an health care facility like hospitals, outpatients clinics, dialysis centers and long term care facilities $[9,10]$.

In a generalized form, Infection prevention and control (IPC) program includes action plan for strengthening IPC for health care facilities and individual units based on the risk assessment. IPC program comprise of a dedicated IPC team responsible to monitor day-to-day activities effective in prevention and control of infection in the health care facility. The team should be responsible for organizing training programs on IPC for HCW's, and develop antibiotic policy and antibiotic stewardship program based on national guidelines along with discussion with the physicians and keeping in mind the local prescribing pattern, conduct surveillance of health care-associated infections (HAI) and should regularly review and revise IPC guidelines. The first step towards implementation of IPC is establishment of IPC program and hospital infection control committee (HICC).

The aim of IPC practices in the context of COVID-19 is to maintain essential health care service and prevent COVID-19 transmission within the health care facility keeping in mind the safety of the HCW (Health Care workers) and patients. The following points briefly highlight the IPC strategies for COVID-19.

There should to strict adherence to standard precautions, these are basic IPC practices to be followed by the healthcare workers(HCWs) for all patients regardless of the disease status of the patient, these includes maintenance of hand hygiene keeping in mind WHO hand hygiene 5 moments, using appropriate product and technique for hand wash/hand rub, maintenance of respiratory hygiene, cough etiquette includes covering nose and mouth with tissue when coughing or sneezing, disposal of the tissue immediately to the nearest waste bin and in the absence of tissue/handkerchief while coughing and sneezing cover nose and mouth with arm and elbow flexed. Use of personal protective equipment (PPE) according to the risk of exposure PPE includes masks, N95 respirators, face shield, goggles, gown, apron, gloves, head cover and shoe cover, implementation of safe injection practices and sharp management, sterilization and disinfection of patient-care equipment's and surroundings, environmental cleaning and ensuring proper waste segregation and management as per the national guidelines [11].

Screening and triage is the first and most critical step in the prevention of transmission of infection to HCW and others. It is important to screen all the persons at first point of contact, this enables early diagnosis and management of the patients. There should be well maintained stations at the entrance for screening and triage. The staff should have adequate PPE kits and should be well trained to recognize signs and symptoms of the patients. The entrance of the HCF should display all signs and symptoms of COVID-19 disease. Social distancing should be maintained at all point of time. There should be provision of rapid testing and reporting in order to identify with persons acute respiratory illness (ARI) at the earliest [11]. Isolation of the patient in a single room if there is availability or else cohort suspected patients and COVID-19 patients separately in separate wards with minimum two meter distance between each bed [12]. Contact and Droplet precautions to be followed [13]. Airborne precautions to be followed only when aerosol-generating procedures (AGP) like intubation, non-invasive ventilation, bronchoscopy, cardiopulmonary resuscitation are performed [14]. Single-use equipment's to be used as much as possible in patients suspected or confirmed with COVID-19. Transportation of such patients should be avoided from one ward to other in case of absolute necessity; such patients can be transferred but should wear face masks while transfer. Minimum visitors and HCW should be in contact with the patient. There should be proper record of all persons entering the patient's room, which is helpful in contact tracing. Regular cleaning and disinfection of the environment is very important in disease control.

Implementation of administrative control includes the establishment of sustainable infrastructure, staff training, ensuring proper doctor-patient ratio, ensuring proper implementation of IPC practices in the HCF and its compliance, developing policies for early diagnosis and management of patient, ensuring access to testing for COVID-19, providing education to care givers establishing surveillance process for acute respiratory illness (ARI) caused by COVID-19 among HCW, preventing overcrowding, repurposing other wards for isolation of COVID-19 patients, providing adequate PPE for the staff and patients [12]. Environmental and engineering controls include adequate ventilation in specific areas of HCF as per national regulations and environmental cleaning. These play an important role in reducing the burden of an infectious agent from the surfaces and inanimate objects. COVID-19 virus can survive in the environment for several hours; premises and areas potentially 
contaminated with the virus to be cleaned before their re-use. Regular cleaning of high touch surfaces like doorknobs, bedrails, light switches, edges of privacy curtains soiled bedding, towels and clothes used by COVID-19 patients should be done on a daily basis or when a patient is discharged. Soiled linen should be placed in a leak proof bag and washed at $60-90{ }^{\circ} \mathrm{C}$ with laundry detergent followed with soaking in $0.1 \%$ chlorine for $30 \mathrm{~min}$ and then dried. Staff handling soiled linens should wear appropriate PPE and perform hand hygiene regularly. Regular cleaning and disinfection of all surfaces that were in contact with patient or may have become contaminated during patient care with Sodium hypochlorite 1\% should be done to clean the surroundings of the patient. In case of spill workers assigned to manage spill should done appropriate PPE and use sodium hypochlorite $1 \%$ in case of small spills and $10 \%$ in case of large spills [15]

Environmental and engineering controls play crucial role in reducing the concentration of infectious respiratory droplets in the air and the contamination of surfaces and inanimate objects. Such controls are very useful especially in the control of COVID-19 virus which primarily spreads through droplet nuclei. Adequate ventilation when aerosol-generating procedure is not done is about 60 liters/sec/h for naturally ventilated area or $6 \mathrm{ACH}$ (air change per hour) for mechanically ventilated area [15]. HCF with natural ventilation should be designed such that the contaminated air from the room is exhausted outside away from crowded areas. The recommended average natural ventilation rate is $160 \mathrm{~L} / \mathrm{s} /$ patient [15]. In the HCF with availability of mechanical ventilation negative pressure rooms should be created with 6-12 ACH and negative pressure $>2.5$ pa. For HCF's which lack adequate natural ventilation or mechanical ventilation, there should be installation of exhaust fan such that the air is expelled directly to outdoors away from ventilation air intake. Installation of roof exhaust system such as whirlybirds may aid in increasing airflow in the building without requiring electrical supply. Spatial separation of at least 1 meter should be maintained between all patients at any point of time. Use of physical barriers like glass or plastic windows can reduce exposure of HCW to COVID-19 virus Use Regular cleaning and disinfection of high touch surfaces, floor and ceilings along with spatial separation, proper ventilation and sterilization and disinfection of medical equipment's used on patients are the various steps important in disease control $[16,17]$

It is advised that all elective surgeries to be postponed and consideration should be made on alternative non-surgical intervention to minimize risk of transmission of infection among patient and staff. It is recommended if the surgical procedure cannot be postponed, careful assessment for risk is to be done to screen the patient for COVID-19 symptoms, in case the patient is symptomatic, investigations should be done for final confirmation however, in case of emergency surgery should not be delayed and the operating staff should adhere to contact and droplet precautions along with use of respirators instead of surgical mask. Patient should wear surgical mask while transfer to the operation theatre. It is preferable if dedicated operation theatre is not available for operating COVID19 patients, it is preferable that room in far corner of surgery floor should be used to perform the procedure. All surgical instruments used during the procedure should be sterilized as per standard protocol. Terminal cleaning should be performed after every surgical procedure as per the guidelines [18].

In the outpatient clinics alternative such as telemedicine for consultation is recommended to avoid face to face interaction with the patient. In case of face to face interaction with a patient such as during examination of the patient, it is advised to follow contact and droplet precautions [19]. The seating arrangement in the clinic should be such that the distance between each patient should be at least 1 meter. HCW handling dead bodies should perform hand hygiene before and after handling body, wear appropriate PPE kit and ensure proper disposal of PPE kit. Although body bags are not necessary for COVID-19 patients but they can be used if there is leakage from body orifices or lack of refrigerated morgue [9].

\section{CONCLUSION}

Implementation of IPC practices and BMWM is a necessary step that should be followed by all, as these practices will help in protection of people involved in health care services, environment and our community as a whole. As HCW we are morally and ethically bound to be vigilant at all time to ensure that IPC practices are followed effectively along with proper segregation of the waste done at the point of generation as per the guidelines laid down by Central Pollution Control Board of India. Proper implementation of the above foresaid IPC practices in the HCF and BMWM in context of proper segregation, collection, storage, transport and final disposal are cornerstone in limiting transmission of COVID-19 among HCW and others.

\section{FUNDING}

Nil

\section{AUTHORS CONTRIBUTIONS}

All the authors have contributed equally.

\section{CONFLICT OF INTERESTS}

\section{Declared none}

\section{REFERENCES}

1. Yuen KS, Ye ZW, Fung SY, Chan CP, Jin DY. SARS-CoV-2 and COVID-19: the most important research questions. Cell Biosci. 2020;10:40

2. Coronavirus Update (Live): 22,040,421 Cases and 777,129 Deaths from COVID-19 Virus Pandemic-Worldometer. Available from: https://www.worldometers.info/coronavirus/ [Last accessed on 18 Aug 2020]

3. Huang C, Wang Y, Li X, Ren L, Zhao J, Hu Y, et al. Clinical features of patients infected with 2019 novel coronavirus in Wuhan, China. Lancet 2020;395:497-506.

4. Advice for the public on COVID-19-World Health Organization Available from: https://www.who.int/emergencies/diseases/ novel-coronavirus-2019/advice-for-public. [Last accessed on 18 Aug 2020].

5. Zhu N, Zhang D, Wang W, Li X, Yang B, Song J, et al. A novel coronavirus from patients with pneumonia in China, 2019. N Engl J Med 2020;382:727-33.

6. Sohrabi C, Alsafi Z, O'Neill N, Khan M, Kerwan A, Al-Jabir A, et al. Corrigendum to "World Health Organization declares Global Emergency: a review of the 2019 Novel Coronavirus (COVID19)". Int J Surg 2020;77:217.

7. De Wit E, van Doremalen N, Falzarano D, Munster VJ. SARS and MERS: recent insights into emerging coronaviruses. Nat Rev Microbiol 2016;14:523-34.

8. Guidelines on preventive measures to contain spread of COVID19 in workplace settings. Ministry of Health and Family Welfare. Available from: https://www.mohfw.gov.in/pdf/ GuidelinesonpreventivemeasurestocontainspreadofCOVID19in workplacesettings.pdf. [Last accessed on 18 Aug 2020].

9. Infection prevention and control during health care when coronavirus disease (COVID-19) is suspected or confirmed World health organization. Available from: https://www.who.int/publications-detail-redirect/WHO2019-nCoV-IPC-2020.4 [Last accessed on 18 Aug 2020]

10. Coronavirus Disease 2019 (COVID-19). Centers for Disease Control and Prevention; 2020. Available from: https://www.cdc.gov/coronavirus/2019-ncov/hcp/non-ussettings/overview/index.html. [Last accessed on 18 Aug 2020]

11. Rational use of personal protective equipment for coronavirus disease (COVID-19) and considerations during severe shortages: interim guidance, 6 April 2020. World Health Organization. Available from: https://apps.who.int/iris/ handle/10665/331695 [Last accessed on 18 Aug 2020]

12. Infection prevention and control of epidemic-and pandemicprone acute respiratory infections in health care. World Health Organization; 2014. Available from: https://apps.who.int/ iris/handle/10665/112656. [Last accessed on 18 Aug 2020]

13. Cleaning and disinfection of environmental surfaces in the context of COVID-19. National Resource for Infection Control (NRIC). Available from: https://www.nric.org.uk/node/54331. [Last accessed on 18 Aug 2020].

14. Clinical management of COVID-19. World health organization. Available from: https://www.who.int/publications-detail- 
redirect/clinical-management-of-covid-19. [Last accessed on 18 Aug 2020].

15. Atkinson J, Chartier Y, Pessoa Silva CL, Jensen P, Li Y, Seto WH. editors. Natural Ventilation for Infection Control in Health-Care Settings. Geneva: World Health Organization; 2009. Available from: http://www.ncbi.nlm.nih.gov/books/NBK143284/. [Last accessed on 18 Aug 2020]

16. ASHRAE 170-2017. Available from: https://www techstreet.com/standards/ashrae-170-2017?product $\mathrm{id}=1999079$.[Last accessed on 18 Aug 2020]

17. Guidelines for Environmental Infection Control in Health-Care Facilities: (545922006-001). American Psychological Association; 2003. Available from: http://doi.apa.org/get-pe- doi. $\mathrm{cfm}$ ?doi=10.1037/e545922006-001. [Last accessed on 18 Aug 2020].

18. Bertsimas D, Dunn J, Velmahos GC, Kaafarani HMA. Surgical risk is not linear: derivation and validation of a novel, userfriendly, and machine-learning-based predictive optimal trees in emergency surgery risk (POTTER) calculator. Ann Surg 2018;268:574-83.

19. Community-based health care, including outreach and campaigns, in the context of the COVID-19 pandemic, Interim guidance; 2020. World Health Organization and the United Nations Children's Fund. Available from: https://www. unicef.org/media/68811/file/Guidance-Community-basedHealth\%20care. [Last accessed on 18 Aug 2020]. 